\title{
A Study on the Implementation of Secure Smart City
}

\author{
Ji-Yeon YOO \\ Department of Intelligent Engineering Informatics for Human \\ Sangmyung University, Republic of Korea
}

\begin{abstract}
In the 21st century, 'Smart City' and 'Smart Community' have been attracting attention in many cities around the world, in order to utilize limited resources effectively and utilize limited resources as well as establish sustainable cities. However, this smart city debate has not been activated as much as I thought. In this study, we discuss the concept of a smart city and examine cyber security issues for smart city implementation. In a Smart City, all of the information of the city is collected, stored, and processed digitally. Therefore, if the information is leaked unauthorizedly or manipulated by external intrusion, the whole city may be paralyzed and personal property and human life may be dangerous.
\end{abstract} Keywords - Smart City, Cyber Security, Secure City

\section{INTRODUCTION}

In the 21st century, 'Smart City' and 'Smart Community' have been attracting attention in many cities around the world in order to utilize limited resources effectively and utilize limited resources while establishing sustainable cities. Many countries, including the United States, are concerned about an explosive demand for limited resource infrastructure, such as food and energy, due to population growth. Information and communication networks are rapidly being improved in all parts of the world, and the convenience of using IT in everyday life such as energy, transportation, security, education, and administration can be widely enjoyed and applied to urban planning in the 21st century.

Machine automation and networking have been progressing in various fields with the development of computers, but with the advent of the Internet of Things (IoT), a society in which all the 'goods' of the world are networked is just around the corner. The development of computers leads to the automation of personal life and business activities, and the development of the internet makes it possible to access massive amounts of information. The internet has given us a chance to broaden the scope of our lives and business activities, by binding each business activity. The wave of informatization has attracted attention as it strengthens economic activity and causes changes in business model. IoT is a product that is integrated into an IT network, which creates new value to products and leads to big changes in the existing business model

Now, the city is a kind of platform with a huge network structure, where many people live together, and a city that incorporates various ICT technologies recently to make the city function properly.

In this study, we discuss the concept of smart city and examine cyber security issues for secure smart city implementation.

What is a 'Smart City'?

\section{SMART CITY CONCEPT AND STRUCTURE MODEL}

There is no international consensus in the definition of a smart city/smart community, but it is generally said to be an effort (or social system itself) to build a sustainable social system using IT or advanced technology.

Smart City is a conceptual urban development model, which means creating a city based on information and communication technology (ICT). The specific definition of smart city differs depending on the economic level and the city policy of the country. Although, it can be seen as a city that uses ICT to improve city competitiveness and quality of life and pursue urban sustainability. Smart City's goals are various, depending on the situation in each country, such as energy efficiency, urban competitiveness, innovation technology development, data opening, urban management efficiency, and citizen participation.

Many countries and cities are seeking to improve the quality of their lives and introduce the idea of a Smart City as a way to enhance the city's competitiveness and sustainability. To achieve this, state-of-the-art ICTs such as Internet of Things (IoT), Big Data, and Cloud Computing are utilized. If the existing city has built roads and power plants, and an expanded police force to solve problems such as traffic, energy, and crime, then a Smart City can provide ICT information. This is done by providing detour information, CCTV monitoring, and real- Improve the efficiency of urban infrastructure and solve problems. 
Based on the European Smart Cities, researchers at the Vienna University of Technology have developed Smart City as a smart economy, smart mobile, smart environment, smart workforce, smart life, as well as a smart governance. The meaning and application of a Smart City will be examined.

\section{[Smart economy]}

It means using ICT technology to enhance the competitiveness of the city while providing higher productivity and economic infrastructure than other cities. In a modern city where people live together, freedom of movement is guaranteed, and if the city does not have regional competitiveness, the city has to fall back and fall, in order to maintain its regional competitiveness. It is expected that a more competitive economic structure will be established in the realization of a more flexible labor capital, international market access, productivity improvement, etc. The concept of 'smart city' itself is aimed at 'improving the quality of citizen's life', and considering that the quality of citizen's lives are largely determined by the size and strength of economic activity. Furthermore, most of the smart city application programs, 'the goal' is to achieve a competitive economy (Smart Economy). Now that internet connectivity is essential to business, Smart City applications can directly affect the city's economic activity.

The remaining five factors are also used to facilitate the use of public services provided by administrative agencies through the use of IT. It also includes efforts to improve the infrastructure of transportation systems and medical systems in terms of IT, and to improve the quality of citizens' lives. It is expected to increase the efficiency of daily life and work for citizens and companies, while and contributing to the creation of more competitive economic activities.

\section{[Smart mobility]}

ICT technology emphasizes the reduction of transportation costs and pollution through organic linkage with transportation system. It is necessary to introduce highly economical public transportation into a Smart City.

In the Smart City, public transportation is an essential element, and the transportation system (Smart Mobility), which improves convenience for consumers while reducing the environmental burden, is one of the important tasks for building a smart city.

Due to the expansion of urban areas due to the influx of local population in modern metropolitan cities, the balance of supply and demand for transportation systems collapses, resulting in increased traffic congestion, commuting time and transportation time, resulting in lower convenience and economic loss of urban life.

\section{[Smart environment]}

It means to properly monitor and protect the natural resources that make up the city with ICT technology.

In a Smart City, investing in IT infrastructure and other infrastructure is also one of the important tasks to improve the environment-friendly infrastructure operating system. It is expected that economic benefits will be achieved, not only in realizing that a city that is livable to ordinary citizens, but also by increasing the efficiency of energy and resource consumption in the whole city. This is also while reducing the energy cost burden for local governments and ordinary citizens.

It is the core of the environment-related business that reduces the environmental burden, while improving the economic efficiency by simultaneously using the IT to achieve high reliability of electric power transmission forecasting, leveling of local electric power and introduction of renewable energy. Especially in the United States, the transmission infrastructure is aging and there is a power loss due to power outages or inefficient transmissions are too large, so it is necessary to improve the power of infrastructure.

Under the Green New Deal policy of the Obama administration, we are striving to build a 'smart grid' that is aware of the use of IT.

\section{[Smart people]}

The city's competitiveness depends on the people living in the city. In Smart City, ICT technology maximizes the ability of people living in the city by utilizing IT. Having a more effective education and talent upbringing is one of the important tasks to accumulate social capital. In New York City, as Bloomberg became a marketplace, the city's top-ranking talent was turned into a city, resulting in a site on Manhattan Island, allowing the world's best technology-based engineering to come in. In the competition, Cornell University won to create a new campus in New York. This will eventually lead to the effect of attracting young people with excellent and talented young people, and the 'people' at high levels play the role of 'social capital' of the city.

In 2009, the ARRA will allocate approximately $\$ 650$ million in total to the dissemination of 'education technology', promoting the use of IT in the educational field and recognizing the need for more effective education. In addition, 
the interesting part of the ARRA budget is that with the use of IT in mind, there are educational achievement goals, such as 'Establishing a database and using data to improve education'.

\section{[Smart living]}

It is one of the important tasks of a Smart City to build a high-level foundation for 'life' of ordinary citizens, as a kind of ICT technology utilization method in terms of improving the quality of life. The introduction of IT in the US medical industry is expected to reduce medical accidents and cut medical costs in countries such as the United States, where medical costs are high.

\section{[Smart Governance]}

This means realizing a high-level administrative base in terms of allowing citizens to easily participate in various decisions related to the city. It is important to make structures so that citizens can do something directly. In other words, it can be the most important factor in creating a smart city, which is to monitor citizen's thoughts in real time, to raise opinions by citizens, and to evaluate them at the same time, in order to make appropriate decisions about the city.

Public services, including security measures, can be considered as a part of the smart city in terms of providing convenient and convenient urban life. This is by providing administrative services to ordinary citizens accurately and efficiently. Open government and electronic administration, which are widely engaged in federal and state governments, are broadly thought to be smart city related businesses.

\section{BACKGROUND ON SMART CITY GETTING ATTENTION}

The smart city has been attracting international attention in the upbringing of future industries. As the demand for urban infrastructure soars, there is a need to reduce public budget in accordance with the global recession.

\section{Demand for Urban Infrastructure Surges}

At present, the urbanization of the population is progressing in many countries of the world, and the demand for city infrastructure is increasing, with the smart city being the focus. According to a U.N. survey, the world population is expected to reach about 10 billion by 2050 , with more than two-thirds expected to live in urban areas. It is also expected that worldwide energy consumption by 2030 will reach about 2.5 times than the 1980 's due to economic growth in developing countries.

In general, it is difficult to adjust the demand for resources due to population growth and urbanization. Therefore, this reflects in the supply side's intention of utilizing limited resources (urban infrastructure) to maximize population growth and urbanization by employing IT.

\section{The Need for Public Budget Reduction Due to the Global Recession}

Since the global recession in 2008 , budgets that were invested in public services and infrastructure in many cities in developed countries, affected by this recession, tended to be compressed, thus, monitoring of their use was strengthened. It is necessary to build an efficient urban infrastructure under the reduced public budget. Efforts to utilize IT to operate the urban infrastructure more efficiently are effective investments that can save money on investment.

Paradoxically, economic measures taken by countries in the wake of the economic downturn are driving smart cities. In the United States, the U.S. Recovery and Reinvestment Act (ARRA), which was established in 2009, decided to inject a large amount of public funds into projects related to smart city-centered activities such as the Smart Grid and medical IT. As for the Smart Grid, there is a survey stating that the initial cost is becoming a barrier to its introduction. In some areas, such as California, there are areas where smart city projects are carried out independently and separate from the ARRA. In many local government agencies with poor financial conditions, the federal government's funding is accelerating the realization of these smart cities.

\section{Fostering Industry for the Future}

The smart city expects investment to be made vigorously around the world, including Smart Grid technology. Smart city global investment is estimated to be around $\$ 41$ trillion worldwide for the next 25 years. As the investment background of the U.S. Smart Grid technology is expected to increase in the future, there is a growing need for investment of about 1.5 to 2 trillion dollars by 2030 for this technology.

In addition, in the above-mentioned economic measures, funds are invested for the purpose of creating demand and revitalizing the economy so that the smart city can be utilized from the viewpoint of industrial nurturing. 


\section{THE SMART CITY'S CYBER SECURITY PROBLEM}

While physical security is important in the existing city, a smart city collects, stores and processes all the information of the city digitally. Therefore, when the information is leaked or manipulated by external intrusion, the entire city is paralyzed, which is why cyber security is essential. Cyber security is a primary responsibility for private operators who develop and install smart city systems and applications. However, since cyber security is a new public resource in the connected digital age, active support from central government and local governments should be done in parallel.

\section{Attack Risk to IT}

The use of IT in a smart city is essential, and securing cyber security is a very important task.

It is particularly considered to be vulnerable to attacks by malicious (external) organizations on lifeline- related infrastructures including energy, which is essential for general citizens and corporate activities.

Also, as the construction of the smart city becomes full-scale in the future, it is expected that the infrastructure of traffic management, education, and medical care will be electronically connected and complicated. Therefore, efforts to secure cyber security in major urban infrastructures are expected to become more important.

\section{Life Log}

In a smart city, data mining using a Life Log can be done based on personal infrastructure utilization by utilizing IT. A smart city distinguishes itself from existing cities. As a major factor, IT can be used to collect detailed information on a citizen's individual infrastructure use and can extract /analyze (data mine) it.

This enables more efficient resource allocation from a macroeconomic viewpoint and enables flexible supply management according to individual needs. As emphasized on the provision of individualized services, data mining using Life Log, which is the same as personal infrastructure usage, is expected to be an important factor that characterizes a smart city.

However, if the Life Log information other than that from the web is collected, the security and privacy of citizens may become difficult, and information-handling methods and security methods are expected to become important issues. Efforts to analyze and utilize the Life Log on an individual's web frequently appear in the form of customized online advertisements and purchase recommendations from online services such as search sites, e-commerce SNS content delivery sites, and the like.

In a smart city, however, personal Life Log collecting activities can be provided in a variety of real-life contexts, as well as on the web and real life.

For example, in the field of healthcare, each individual acquires a medical sensor, and health information is always uploaded to the primary care physician, so that the diagnosis and treatment can be performed more quickly. It is expected that the privacy demand of an individual 's Life Log will increase, and the development of a collection and analysis method of various information and the safeguarding of information security will be crucial.

\section{Risks Due to Poor IT Utilization}

In order to take advantage of advanced infrastructure in the creation of new cities, we must nurture and secure talent. Even if the advanced infrastructure that constitutes a smart city is established, it is difficult for the operator or the administrative organization to manage the city efficiently if it lacks the personnel to deal with it. Therefore, efforts to improve IT utilization ability are expected to accelerate in the future.

In fact, the U.S. DOE's Smart Grid Talent Development Program is an example of this move to secure the ability of IT administrators to utilize IT infrastructure, in terms of infrastructure operation and construction.

In addition, if there is a difference in the citizens' level of IT literacy, some citizens will not be fully able to enjoy the benefits of a smart city, and measures will need to be taken to boost IT utilization. For example, about $79 \%$ of U.S. consumers are unfamiliar with smart grids, so adopting only smart grid infrastructures with low IT literacy capabilities may not lead to efficient city operations. That is, if a smart meter is placed in each household to report the energy use of individual household appliances, but the consumer does not know how to use the data, this may not equate to energy saving.

The smart city will enhance the convenience of city dwellers and will require the ability of IT staff to use IT, while the smart city life itself will be integrated with IT utilization, this will lead to the improvement of the ability of the whole population to use IT. 
Relationship Between Connectivity and Privacy

Contrary to the positive value of ICT technology and IoT's connectivity, ICT users are concerned about privacy issues. This means that business models, systems, and policies should be simultaneously created to enhance the level of connectivity and privacy through appropriate technology development and institutionalization.

Linkage without deliberately addressing privacy concerns raises concerns about privacy violations, which can eventually lead to unnecessary controversy and social costs in the development of a smart city.

It is important to recognize that increasing connectivity does not always result in a loss of privacy, and that policy makers, operators, and users will recognize that new systems and business models are available to increase connectivity and privacy at the same time. It is necessary to make efforts to make it possible.

\section{REFERENCE}

[1] Angelidou, M., 'Smart city policies: A spatial approach', Cities, 41, 2014, pp. S3-S11

[2] J. Y., Lee, and H. S., Sagong (2015). 「Smart City Overseas Trends and Implications」, 「National Policy Brief」 no. 529, KRIHS, 2015. p.3. 